\title{
Mitochondria as signaling organelles
}

\author{
Navdeep S Chandel
}

\begin{abstract}
Almost 20 years ago, the discovery that mitochondrial release of cytochrome $c$ initiates a cascade that leads to cell death brought about a wholesale change in how cell biologists think of mitochondria. Formerly viewed as sites of biosynthesis and bioenergy production, these double membrane organelles could now be thought of as regulators of signal transduction. Within a few years, multiple other mitochondria-centric signaling mechanisms have been proposed, including release of reactive oxygen species and the scaffolding of signaling complexes on the outer mitochondrial membrane. It has also been shown that mitochondrial dysfunction causes induction of stress responses, bolstering the idea that mitochondria communicate their fitness to the rest of the cell. In the past decade, multiple new modes of mitochondrial signaling have been discovered. These include the release of metabolites, mitochondrial motility and dynamics, and interaction with other organelles such as endoplasmic reticulum in regulating signaling. Collectively these studies have established that mitochondria-dependent signaling has diverse physiological and pathophysiological outcomes. This review is a brief account of recent work in mitochondria-dependent signaling in the historical framework of the early studies.
\end{abstract}

Hans Krebs won the Nobel Prize in Physiology or Medicine in 1953 for his discovery of the citric acid cycle. In his Nobel Lecture, Krebs stated, 'that in some microorganisms the cycle primarily supplies intermediates rather than energy, whilst in the animal and most other organisms it supplies both energy and intermediates'. This essentially describes the two salient functions of mitochondria described in most biochemistry textbooks: production of ATP, and the generation of intermediary

\footnotetext{
Correspondence: nav@northwestern.edu

Section of Pulmonary and Critical Care Medicine, Department of Medicine,

Feinberg School of Medicine, Northwestern University, Chicago, IL 60611,
} USA

\section{() Biomed Central}

(c) 2014 Chandel; licensee BioMed Central Ltd. This is an Open Access article distributed under the terms of the Creative Commons Attribution License (http://creativecommons.org/licenses/by/2.0), which permits unrestricted use, distribution, and reproduction in any medium, provided the original work is properly cited. metabolites. The citric acid cycle, commonly referred to as the TCA cycle, generates metabolites and reducing equivalents (NADH and FADH2). Electrons from reducing equivalents feed into the mitochondrial electron transport chain (ETC), which pumps protons across the mitochondrial inner membrane to generate an electrochemical gradient that is required both for production of ATP and for the efficient shuttling of proteins into and out of mitochondria. Mitochondrial ATP generation allows cells to maintain a high ATP/ADP ratio, which is necessary to thermodynamically drive many biochemical reactions. Mitochondria are also involved in the generation of proteins that contain heme and porphyrin moieties, a process dependent on membrane potential. The metabolites generated by the TCA cycle are precursors to the biosynthesis of many macromolecules, including lipids, carbohydrates, proteins and nucleotides. Thus, mitochondria have historically been viewed as bioenergetic and biosynthetic organelles; however, mitochondrial genetics has demonstrated that alterations in proteins that have similar effects on TCA cycle and ETC activity often yield divergent phenotypes, suggesting that mitochondrial perturbation must manifest beyond biosynthesis and bioenergetics.

In the past two decades, the reason for this has become clear, as it has been increasingly appreciated that mitochondria have developed mechanisms to communicate their biosynthetic and bioenergetics fitness to the rest of the cell and thus have signaling functions beyond their metabolic ones (Figure 1). One critical function of these is to ensure that cells do not become committed to a biological process without input on the fitness of mitochondria, risking a discrepancy between the metabolic demands of the cell and the ability of the mitochondria to meet them. In the 1990s, multiple groups pioneered the idea that mitochondria communicate with the cytosol. Their observations included (1) mitochondrial release of cytochrome $c$ to initiate cell death [1]; (2) mitochondrial release of reactive oxygen species (ROS) to activate hypoxic gene expression [2]; (3) the localization of A-kinase-anchoring proteins (AKAPs) to the mitochondrial outer membrane, allowing cAMP-dependent protein 




Figure 1. Three essential functions of mitochondria. Mitochondria have three distinct functions in the maintenance of homeostasis: bioenergetics, biosynthesis, and signaling.

kinase (PKA) to phosphorylate substrates on the outer mitochondrial membrane [3,4]; and (4) mitochondrial dysfunction causing induction of mitochondria-specific heat shock proteins and promoting cytosolic calciumdependent signaling $[5,6]$.

These studies led to the emerging concept that mitochondria are signaling organelles either through the release of proteins, ROS, or metabolites, or by serving as a scaffold to configure signaling complexes (Figure 2). In the new millennium, multiple other mechanisms have been uncovered by which mitochondria communicate with the rest of the cell. Signal transduction from mitochondria to the cytosol is referred to as retrograde signaling and signal transduction from cytosol to mitochondria as anterograde signaling, and the insights of the 1990s included those emerging from studies on anterograde signaling, most notably through cytosolic calcium entering into mitochondria to regulate bioenergetics [7]. In this review, however, I will discuss only the retrograde signaling mechanisms whereby mitochondria communicate with the cell under physiological and pathological conditions.

\section{Mitochondrial cytochrome c release regulates signaling}

In the mid-1990s, the biology related to mitochondrial genetics was an exciting and rapidly evolving field. Mitochondria contain their own genome, which encodes a small percentage of mitochondrial proteins, with the majority encoded by nuclear DNA. How mitochondrial DNA integrates with nuclear DNA to make cells function and how miscommunication between the two types of DNA can lead to pathology continues to be a fascinating question [8]. By contrast, there was a sense that every question related to the biochemistry of mitochondria had been answered. The field's best days were in the past. Nevertheless, I had pursued a PhD on the oxygen dependence of cytochrome c oxidase $[9,10]$ because I thought there might be interesting biochemistry under limiting oxygen conditions (hypoxia), a condition prominent in tumors, ischemic diseases and during development in utero. Thus, it came as a complete surprise when in 1996 Xiaodong Wang and colleagues, using biochemical approaches, reported that cytochrome $\mathrm{c}$ is released from mitochondria to initiate cell death in mammalian cells [1]. Cytochrome $\mathrm{c}$ is an electron carrier in the mitochondria and is an essential component of the electron transport chain, and ultimately necessary for ATP generation. To me, this seemed an extraordinarily important discovery in research on mitochondria. It reenergized interest not only in the biochemical activities of mitochondria, but also in how this organelle is integrated with the rest of the cell. Soon multiple labs around the world were examining the mechanisms leading to release of cytochrome $\mathrm{c}$ in cells that have been instructed to die [11-13]. This led to the examination of mitochondrial ATP generation, membrane potential, and oxygen consumption in cells committed to death - all of which were things I understood. But, beyond its seminal role in cell death, the discovery of the apoptotic release of cytochrome $\mathrm{c}$ opened the possibility that there might be other mechanisms by which mitochondria communicate with the cell, especially under physiological conditions. It was difficult to imagine that mitochondria would play a signaling role only under conditions leading to cell death.

\section{Mitochondrial ROS regulate signaling}

In the mid-1990s, NADPH oxidase activity had been demonstrated to promote signaling pathways involved in

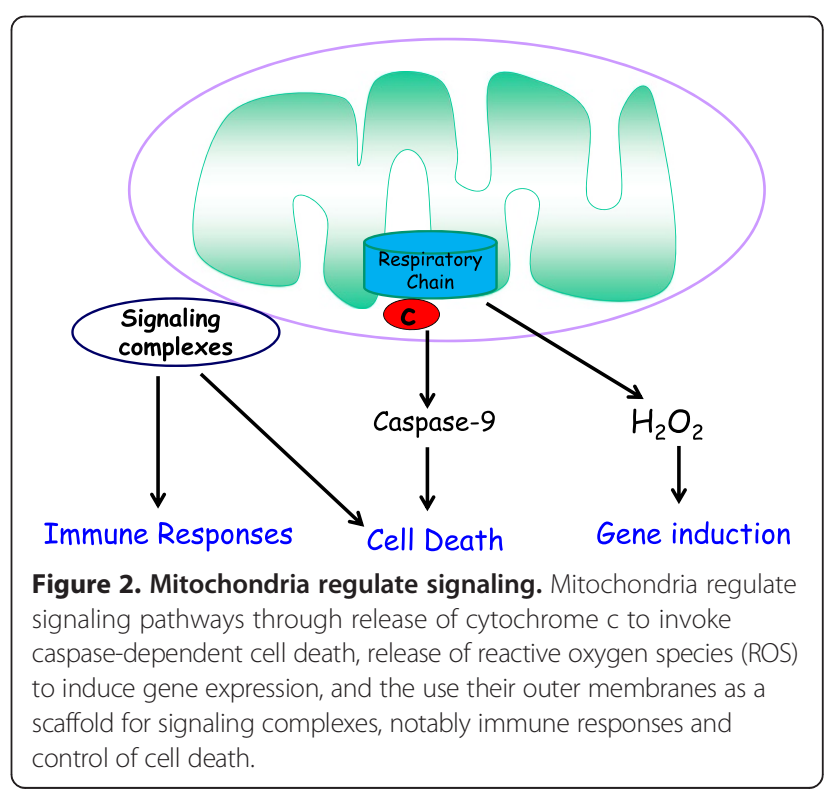


cell proliferation through oxidation of particular cysteine residues in proteins, modulating their activity [14-16]. By contrast, mitochondrial ROS (mROS) were proposed to be produced only under pathological conditions to invoke damage [17]. However, in the late 1990s, mROS emerged as signaling molecules that communicate between mitochondria and the rest of the cell under physiological conditions. An early example of this retrograde signaling under physiological conditions is the observation that hypoxic conditions stimulate mitochondria to release ROS, resulting in the stabilization of hypoxia inducible factors (HIFs) and the induction of genes responsible for metabolic adaptation to low oxygen $[2,18]$. Subsequently, mROS were shown to regulate cellular metabolism and tumor necrosis factor receptor signaling [19-21]. Eight sites in the mitochondrial inner membrane and matrix have been implicated in the production of ROS [22]. The factors that control mROS production include the concentration of oxygen available to mitochondria, the redox state of the different electron transport chain complexes and mitochondrial membrane potential [23]. In the past decade, mROS have been shown to regulate a wide range of biological processes, including oxygen sensing, epigenetics, autophagy, innate and adaptive immune responses, stem cell proliferation and differentiation, and hormone signaling [24-28].

A scientific colleague and friend once quipped, 'If you don't have a mechanism just say it is ROS'. There is some justification for this remark, since ROS have been linked to a wide variety of biological outcomes, including proliferation, differentiation, metabolic adaptation and senescence, though with no insight into the specific mROS targets required to invoke such diverse biological outcomes, or the mechanism involved. It is important to note that mROS targets that relay signaling could be localized in any or all of the mitochondrial matrix, the intermembrane space, or the cytosol. Furthermore, given the reactivity and toxicity of ROS at high levels, it seems likely that lower levels of mROS may be generated that invoke distinct biological outcomes. Control of different stem cell fates by ROS is an example of different levels of ROS invoking different biological outcomes. The two salient features of stem cells are their ability to selfrenew, and their ability to differentiate into specialized tissues $[29,30]$. An emerging model is that quiescent stem cells reside at low levels of ROS and slight increases in ROS are necessary signals for self-renewal and cellular differentiation [31-33]. ROS levels above those required for self-renewal or differentiation impair these critical two stem cell properties and result in stem cell hyper-proliferation, resulting in stem cell exhaustion [34]. Going forward, it will be important to systematically quantify the ROS levels generated by mitochondria and their targets that are necessary for stem cell proliferation, differentiation and exhaustion in a given stem cell model system.

One interesting development over the past two decades has been the change in perspective on the role of mROS signaling in aging. Originally the free radical theory of aging proposed that, during the aging process, damaged mitochondria produced increasing amounts of ROS leading to tissue damage [35]. However, in most studies antioxidants have not extended lifespan of model organisms and clinical trials using antioxidants in humans have not shown any beneficial effects on agerelated diseases [36]. On the contrary, recent evidence in yeast, Caenorhabditis elegans, and mice suggests that increasing mitochondrial generation of ROS can activate cellular stress pathways to dampen tissue degeneration, promote healthy aging and increase lifespan [37-40]. Based on the studies from the past two decades, an emerging model of mROS and signaling suggests that low levels (picomolar to nanomolar range) of mROS are necessary to maintain homeostatic biological processes, while slightly elevated levels of mROS initiate pathways for adaptation to stress. Much higher levels of mROS trigger cell death or senescence.

\section{Mitochondrial outer membrane as a platform for signaling}

In the mid-1990s it was shown that AKAPs could be tethered to the outer mitochondrial membrane and, in subsequent years, the targeting motifs needed for AKAP binding to outer mitochondrial membrane were elucidated $[4,41]$. AKAPs bind to the cAMP-dependent serine/threonine kinase PKA and assemble PKA with multiple signaling proteins on a scaffold to generate a signaling hub, which can be targeted to various subcellular localizations to allow specific targeting of PKAdependent signaling [42]. The biological significance of AKAP tethering to mitochondria was demonstrated in the late 1990s when it was shown that survival factors induce PKA-dependent phosphorylation and inactivation of BAD, a proapoptotic Bcl2 family member, specifically bound to outer mitochondrial membrane [3]. Beyond apoptosis, recent studies demonstrate that BAD tethering to mitochondria also regulates organismal glucose homeostasis $[43,44]$. In the past decade, mitochondriabound PKA-AKAP assemblies have been shown to regulate oxidative metabolism, the mitochondrial fission/fusion machinery, and hypoxic responses [45,46]. This allows cellular signaling pathways to converge on the mitochondrial PKA-AKAP axis to control mitochondrial function. AKAPs have been shown to not only anchor PKA, but also act as scaffolding proteins to coordinate the activity of many other signaling enzymes such as kinases and phosphatases [47]. Thus, it is likely that there are multiple other AKAP-dependent but PKA-independent 
signaling pathways tethered to the outer mitochondrial membrane that remain to be discovered.

The mitochondrial outer membrane also serves as a scaffold for complexes regulating immune responses. This was first highlighted in the mid-2000s by the identification of mitochondrial antiviral signaling protein (MAVS), a crucial adaptor for RIG-I-like receptor signaling [48]. RIG-I recognizes single-stranded viral RNA and subsequently activates type I interferon production through MAVS, which is localized to the outer mitochondrial membrane $[49,50]$. Type-I interferons (IFN $\alpha / \beta)$ are secreted very soon after virus infection. Infected cells generate IFN $\beta$ followed shortly by the production of IFN $\alpha$. Type I interferons activate interferon-stimulated genes (ISGs) as well as the NF- $\kappa \mathrm{B}$ pathway. ISGs encode antiviral proteins that produce an anti-viral state in surrounding cells in close proximity to the infected cells, to limit the spread of the virus. The activation of the NK- $\mathrm{kB}$ pathway leads to the production of several proinflammatory cytokines and chemokines that lead to infiltration of circulating innate cells and eventually adaptive immune $\mathrm{T}$ and B cells. This helps control the viral infection [51]. Recently, other innate immune molecules involved in NOD-like receptor (NLR) and TOLL-like receptor (TLR) signaling have been functionally associated with the outer mitochondrial membrane [52-54]. Exactly why these immune complexes require localization to the outer mitochondrial membrane is not fully understood [55]. Mitochondria-generated ROS are necessary for optimal function of many immune responses, and thus proximity to ROS production could be one reason why immune complexes are tethered to the outer mitochondrial membrane [56,57]. It is interesting that mitochondria are evolutionarily related to alphaproteobacteria, and thus are descended from symbiotic pathogens. We continue to be dependent on our own pathogen - mitochondria - to mount optimal responses against foreign pathogens.

\section{Mitochondrial dysfunction and signaling}

So far I have described mitochondrial signaling in the context of physiologic homeostasis. However, there are conditions where mitochondria become dysfunctional. Mitochondrial dysfunction, defined as the inability to generate ATP or metabolites, or import/export proteins, can arise when a substrate such as oxygen becomes limiting for ETC function, or through genetic alterations that lead to impairment of mitochondrial proteins. How do dysfunctional mitochondria communicate with the rest of the cell? An early clue that mitochondrial dysfunction can induce cellular responses came from the observation in the mid-1990s that the loss of mitochondrial DNA can induce nuclear encoded mitochondrial heat shock proteins (HSPs) but not cytosolic HSPs [5].

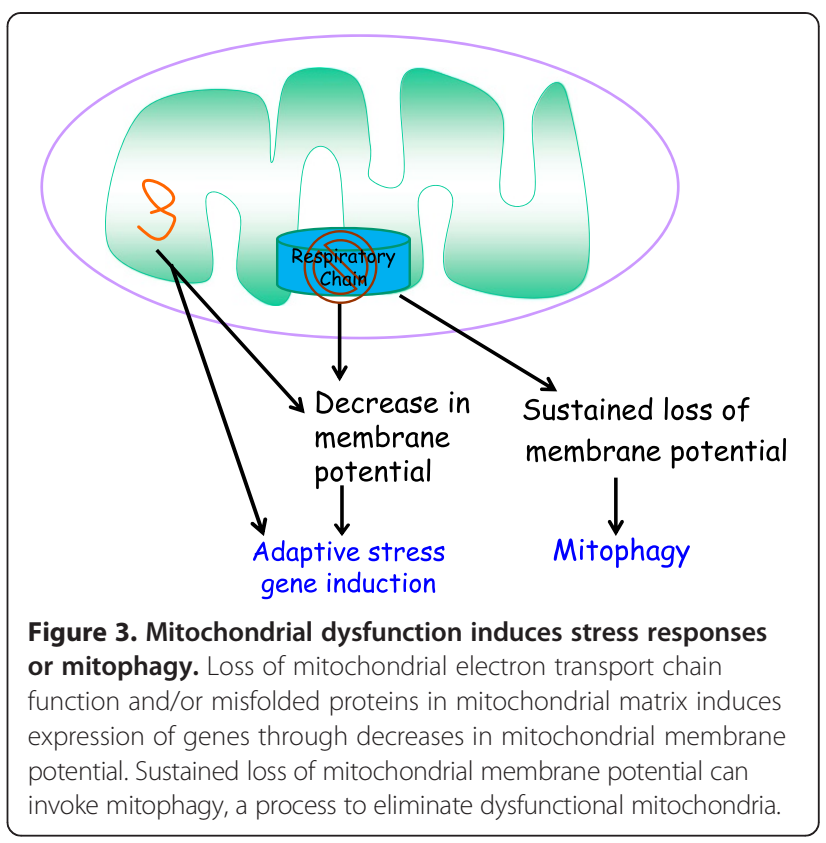

In the late 1990s, decreased mitochondrial membrane potential resulting in an increase in cytosolic calcium was one mechanism elucidated by which loss of mitochondrial DNA activates signaling pathways [6]. Subsequent studies demonstrated that accumulation of unfolded proteins within the mitochondrial matrix results in the induction of mitochondria-specific HSPs, a process referred to as the mitochondrial-unfolded response (mtUPR) [58]. The significance of the mtUPR began to be unraveled in the late 2000s by the discovery of pathways that induce the mtUPR in C. elegans $[59,60]$. Further studies demonstrated that activation of the mtUPR by mitochondrial dysfunction could increase lifespan in C. elegans [61,62]. Although slight or transient mitochondrial dysfunction induces adaptive stress responses, sustained mitochondrial dysfunction typically leads to elimination of mitochondria by mitophagy [63]. A given cell can contain sets of mitochondria that are functional and dysfunctional. The dysfunctional mitochondria can send signals to induce stress responses such as induction of mitochondrial HSPs until mitophagy eliminates them (Figure 3). Impairment of mitophagy can result in accumulation of dysfunctional mitochondria and disruption of calcium homeostasis, overproduction of ROS, and loss of metabolite and ATP production, all leading to the demise of the cell $[64,65]$.

\section{Emerging modes of communication between mitochondria and the cell}

In the past few years, other interesting modes of communication between mitochondria and the rest of the 
cell have been discovered. These include release of metabolites, activation of AMPK, and changes in mitochondrial dynamics. Briefly I will highlight these lively new areas. Metabolite availability has emerged as an important mechanism to control signal transduction, notably the acetylation and methylation of DNA and histones regulating epigenetics [66]. Mitochondria generate much of the acetyl-CoA and S-Adenosylmethionine (SAM) needed for protein acetylation and methylation, respectively. Thus, changes in mitochondrial biology can have profound effects on the epigenetic state [67-69]. Metabolic enzymes can also undergo acetylation at specific residues that affect their catalytic function [70]. Loss of ATP production by mitochondria (for example, during ischemia) can also regulate signaling through increasing levels of AMP and its breakdown product adenosine. The increase in AMP levels concomitant with a decrease in ATP levels activates the kinase AMPK, which halts multiple anabolic processes (metabolic demand) in the cell and promotes catabolic processes such as autophagy to ensure ample metabolic supply [71]. Adenosine can be released from cells where it engages in activation of G-protein-coupled receptors [72,73]. Thus, metabolites and adenine nucleotides typically thought of being involved in biosynthetic and bioenergetic processes are also actively involved in signaling.

The cell biology of mitochondria has rapidly evolved in the past decade, bringing about the new field of mitochondrial dynamics [74]. While the molecular details of how mitochondria move throughout the cell are still being elucidated, it is known that the ability of mitochondria to properly move around in the cell is required to properly disseminate their signals to the correct targets [75]. For example, hypoxia causes mitochondria to cluster into the perinuclear region, allowing release of ROS into the nucleus for optimal hypoxic gene expression [76]. Mitochondria in healthy cells tend to be elongated and fuse together into 'spaghetti' like filamentous structures. The rate of fusion and fission of mitochondria is tightly controlled [77]. Excessive fission disrupts these filamentous networks, resulting in a punctate pattern and mitochondrial dysfunction. A recent study highlights how the fission/fusion machinery integrates with cellular signaling to dictate biological outcomes. The disruption of fusion in mouse embryonic heart and in embryonic stem cells results in disruption of mouse heart development and impaired differentiation of embryonic stem cells into cardiomyocytes due to increased $\mathrm{Ca}^{2+}$-dependent calcineurin activity and Notch1 signaling [78].

Lastly, mitochondria tether to specific subdomains of the endoplasmic reticulum (ER) referred to as mitochondria-associated membranes or MAMs [79].

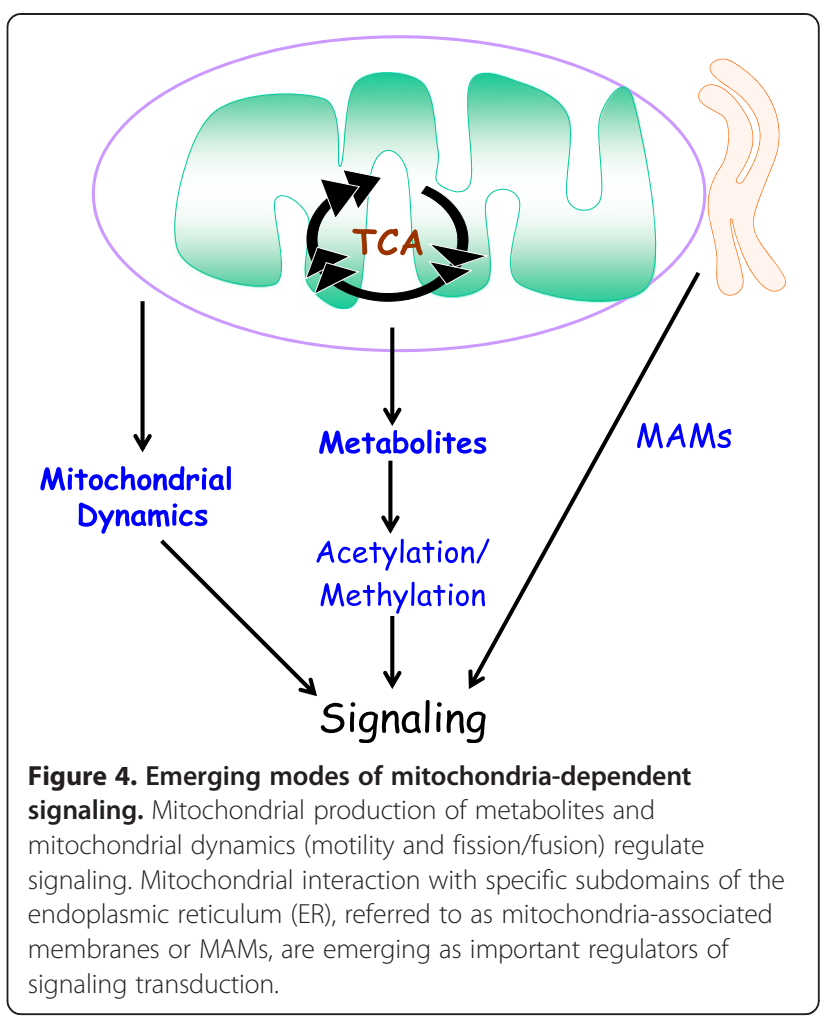

Initially, MAMs were shown to be necessary for rapid transmission of calcium $\left(\mathrm{Ca}^{2+}\right)$ signals between the ER and mitochondria to regulate intracellular calcium levels [80]. Recent studies have demonstrated that MAMs regulate mitochondrial motility and shape, ROS and ATP production, autophagy, ER stress and immune signaling [81].

All these modes of communication are summarized in Figure 4.

\section{Conclusion}

In the past decade, there has been an explosion of scientific inquiry in the areas of mitochondrial genetics, cell biology and biochemistry [82]. Work in these fields is increasingly converging on the control of signaling events in the rest of the cell, with important implications for regulation of physiology and common diseases. Although much has been deciphered about the types of signaling modes whereby mitochondria communicate with the rest of the cell, the molecular details remain sparse. A better understanding of the underlying mechanisms will hopefully yield insight into how to alleviate common diseases such as diabetes, cancer, and neurodegeneration, as well as provide insight into the early evolution of eukaryotes. 


\section{Acknowledgements}

I would like to thank Dr Robert Hamanka for his excellent comments on this review. This work is supported by R01CA123067 and 5P01HL071643.

Published: 27 May 2014

\section{References}

1. Liu X, Kim CN, Yang J, Jemmerson R, Wang X: Induction of apoptotic program in cell-free extracts: requirement for dATP and cytochrome $c$. Cell 1996, 86:147-157.

2. Chandel N, Maltepe E, Goldwasser E, Mathieu C, Simon M, Schumacker P. Mitochondrial reactive oxygen species trigger hypoxia-induced transcription. Proc Natl Acad Sci U S A 1998, 95:11715-11720.

3. Harada H, Becknell B, Wilm M, Mann M, Huang LJ, Taylor SS, Scott JD, Korsmeyer SJ: Phosphorylation and inactivation of BAD by mitochondria-anchored protein kinase A. Mol Cell 1999, 3:413-422.

4. Chen Q, Lin RY, Rubin CS: Organelle-specific targeting of protein kinase All (PKAII). Molecular and in situ characterization of murine A kinase anchor proteins that recruit regulatory subunits of PKAll to the cytoplasmic surface of mitochondria. J Biol Chem 1997, 272:15247-15257.

5. Martinus RD, Garth GP, Webster TL, Cartwright P, Naylor DJ, Hoj PB, Hoogenraad NJ: Selective induction of mitochondrial chaperones in response to loss of the mitochondrial genome. Eur J Biochem 1996, 240:98-103

6. Biswas G, Adebanjo OA, Freedman BD, Anandatheerthavarada HK, Vijayasarathy C, Zaidi M, Kotlikoff M, Avadhani NG: Retrograde Ca2+ signaling in $\mathrm{C} 2 \mathrm{C} 12$ skeletal myocytes in response to mitochondrial genetic and metabolic stress: a novel mode of inter-organelle crosstalk. EMBO J 1999, 18:522-533.

7. Rizzuto R, Brini M, Murgia M, Pozzan T: Microdomains with high Ca2+ close to IP3-sensitive channels that are sensed by neighboring mitochondria. Science 1993, 262:744-747.

8. Wallace D: A mitochondrial paradigm of metabolic and degenerative diseases, aging, and cancer: a dawn for evolutionary medicine. Annu Rev Genet 2005, 39:359-407.

9. Chandel NS, Budinger GR, Schumacker PT: Molecular oxygen modulates cytochrome c oxidase function. J Biol Chem 1996, 271:18672-18677.

10. Chandel N, Budinger G, Choe S, Schumacker P: Cellular respiration during hypoxia. Role of cytochrome oxidase as the oxygen sensor in hepatocytes. J Biol Chem 1997, 272:18808-18816.

11. Vander Heiden MG, Chandel NS, Williamson EK, Schumacker PT, Thompson $\mathrm{CB}: \mathrm{BCl}-\mathrm{xL}$ regulates the membrane potential and volume homeostasis of mitochondria. Cell 1997, 91:627-637.

12. Kluck RM, Bossy-Wetzel E, Green DR, Newmeyer DD: The release of cytochrome c from mitochondria: a primary site for $\mathrm{Bcl}-2$ regulation of apoptosis. Science 1997, 275:1132-1136.

13. Gross A, Jockel J, Wei MC, Korsmeyer SJ: Enforced dimerization of BAX results in its translocation, mitochondrial dysfunction and apoptosis. EMBO J 1998, 17:3878-3885.

14. Irani K, Xia Y, Zweier JL, Sollott SJ, Der CJ, Fearon ER, Sundaresan M, Finkel T, Goldschmidt-Clermont PJ: Mitogenic signaling mediated by oxidants in Ras-transformed fibroblasts. Science 1997, 275:1649-1652.

15. Sundaresan $M, Y u Z$, Ferrans $V$, Irani $K$, Finkel T: Requirement for generation of $\mathrm{H} 2 \mathrm{O} 2$ for platelet-derived growth factor signal transduction. Science 1995, 270:296-299.

16. Bae YS, Kang SW, Seo MS, Baines IC, Tekle E, Chock PB, Rhee SG: Epiderma growth factor (EGF)-induced generation of hydrogen peroxide. Role in EGF receptor-mediated tyrosine phosphorylation. J Biol Chem 1997, 272:217-221.

17. Shigenaga MK, Hagen TM, Ames BN: Oxidative damage and mitochondrial decay in aging. Proc Natl Acad Sci U S A 1994, 91:10771-10778.

18. Chandel NS, McClintock DS, Feliciano CE, Wood TM, Melendez JA Rodriguez AM, Schumacker PT: Reactive oxygen species generated at mitochondrial complex III stabilize hypoxia-inducible factor-1alpha during hypoxia: a mechanism of $\mathrm{O} 2$ sensing. J Biol Chem 2000, 275:25130-25138

19. Chandel N, Trzyna W, McClintock D, Schumacker P: Role of oxidants in NF-kappa B activation and TNF-alpha gene transcription induced by hypoxia and endotoxin. J Immunol 2000, 165:1013-1021.
20. Chandel N, Schumacker $P$, Arch R: Reactive oxygen species are downstream products of TRAF-mediated signal transduction. J Biol Chem 2001, 276:42728-42736.

21. Nemoto S, Takeda K, Yu ZX, Ferrans VJ, Finkel T: Role for mitochondrial oxidants as regulators of cellular metabolism. Mol Cell Biol 2000, 20:7311-7318

22. Brand MD: The sites and topology of mitochondrial superoxide production. Exp Gerontol 2010, 45:466-472.

23. Murphy M: How mitochondria produce reactive oxygen species. Biochem J 2009, 417:1-13.

24. West AP, Shadel GS, Ghosh S: Mitochondria in innate immune responses. Nat Rev Immunol 2011, 11:389-402.

25. Schroeder EA, Raimundo N, Shadel GS: Epigenetic silencing mediates mitochondria stress-induced longevity. Cell Metab 2013, 17:954-964.

26. Collins Y, Chouchani ET, James AM, Menger KE, Cocheme HM, Murphy MP: Mitochondrial redox signalling at a glance. J Cell Sci 2012, 125:801-806.

27. Sena LA, Chandel NS: Physiological roles of mitochondrial reactive oxygen species. Mol Cell 2012, 48:158-167.

28. Hamanaka $\mathrm{R}$, Chandel $\mathrm{N}$ : Mitochondrial reactive oxygen species regulate hypoxic signaling. Curr Opin Cell Biol 2009, 21:894-899.

29. Sahin E, Depinho RA: Linking functional decline of telomeres, mitochondria and stem cells during ageing. Nature 2010, 464:520-528.

30. Signer RA, Morrison SJ: Mechanisms that regulate stem cell aging and life span. Cell Stem Cell 2013, 12:152-165.

31. Liu J, Finkel T: Stem cells and oxidants: too little of a bad thing. Cell Metab 2013, 18:1-2.

32. Xu X, Duan S, Yi F, Ocampo A, Liu GH, JC IB: Mitochondrial regulation in pluripotent stem cells. Cell Metab 2013, 18:325-332.

33. Hamanaka RB, Glasauer A, Hoover P, Yang S, Blatt H, Mullen AR, Getsios S, Gottardi CJ, DeBerardinis RJ, Lavker RM, Chandel NS: Mitochondrial reactive oxygen species promote epidermal differentiation and hair follicle development. Sci Signal 2013, 6:ra8

34. Liu J, Cao L, Finkel T: Oxidants, metabolism, and stem cell biology. Free Radic Biol Med 2011, 51:2158-2162.

35. Harman D: Aging: a theory based on free radical and radiation chemistry. J Gerontol 1956, 11:298-300.

36. Bjelakovic G, Nikolova D, Gluud LL, Simonetti RG, Gluud C: Mortality in randomized trials of antioxidant supplements for primary and secondary prevention: systematic review and meta-analysis. JAMA 2007, 297:842-857.

37. Ristow M, Schmeisser S: Extending life span by increasing oxidative stress. Free Radic Biol Med 2011, 51:327-336

38. Hekimi S, Lapointe J, Wen Y: Taking a 'good' look at free radicals in the aging process. Trends Cell Biol 2011, 21:569-576.

39. Liu X, Jiang N, Hughes B, Bigras E, Shoubridge E, Hekimi S: Evolutionary conservation of the clk-1-dependent mechanism of longevity: loss of mclk1 increases cellular fitness and lifespan in mice. Genes Dev 2005, 19:2424-2434

40. Schulz TJ, Zarse K, Voigt A, Urban N, Birringer M, Ristow M: Glucose restriction extends Caenorhabditis elegans life span by inducing mitochondrial respiration and increasing oxidative stress. Cell Metab 2007, 6:280-293.

41. Huang $L J$, Wang $L, M a ~ Y$, Durick $K$, Perkins G, Deerinck TJ, Ellisman MH, Taylor SS: NH2-Terminal targeting motifs direct dual specificity A-kinase-anchoring protein 1 (D-AKAP1) to either mitochondria or endoplasmic reticulum. J Cell Biol 1999, 145:951-959.

42. Taylor SS, Zhang P, Steichen JM, Keshwani MM, Kornev AP: PKA: lessons learned after twenty years. Biochim Biophys Acta 1834, 2013:1271-1278.

43. Gimenez-Cassina A, Garcia-Haro L, Choi CS, Osundiji MA, Lane EA, Huang $H_{t}$ Yildirim MA, Szlyk B, Fisher JK, Polak K, Patton E, Wiwczar J, Godes M, Lee DH, Robertson K, Kim S, Kulkarni A, Distefano A, Samuel V, Cline G, Kim YB, Shulman Gl, Danial NN: Regulation of hepatic energy metabolism and gluconeogenesis by BAD. Cell Metab 2014, 19:272-284.

44. Danial NN, Walensky LD, Zhang CY, Choi CS, Fisher JK, Molina AJ, Datta SR, Pitter KL, Bird GH, Wikstrom JD, Deeney JT, Robertson K, Morash J, Kulkarni A, Neschen S, Kim S, Greenberg ME, Corkey BE, Shirihai OS, Shulman Gl, Lowell BB, Korsmeyer SJ: Dual role of proapoptotic BAD in insulin secretion and beta cell survival. Nat Med 2008, 14:144-153.

45. Carlucci A, Lignitto L, Feliciello A: Control of mitochondria dynamics and oxidative metabolism by CAMP, AKAPs and the proteasome. Trends Cell Biol 2008, 18:604-613. 
46. Kim H, Scimia MC, Wilkinson D, Trelles RD, Wood MR, Bowtell D, Dillin A, Mercola M, Ronai ZA: Fine-tuning of Drp1/Fis1 availability by AKAP121/ Siah2 regulates mitochondrial adaptation to hypoxia. Mol Cell 2011, 44:532-544.

47. Esseltine $J L$, Scott JD: AKAP signaling complexes: pointing towards the next generation of therapeutic targets? Trends Pharmacol Sci 2013, 34:648-655

48. Seth RB, Sun L, Ea CK, Chen ZJ: Identification and characterization of MAVS, a mitochondrial antiviral signaling protein that activates NF-kappaB and IRF 3. Cell 2005, 122:669-682.

49. Koshiba T: Mitochondrial-mediated antiviral immunity. Biochim Biophys Acta 1833, 2013:225-232

50. Belgnaoui SM, Paz S, Hiscott J: Orchestrating the interferon antiviral response through the mitochondrial antiviral signaling (MAVS) adapter. Curr Opin Immunol 2011, 23:564-572.

51. Takeuchi O, Akira S: Pattern recognition receptors and inflammation. Cell 2010, 140:805-820.

52. West AP, Brodsky IE, Rahner C, Woo DK, Erdjument-Bromage H, Tempst $P$, Walsh MC, Choi Y, Shadel GS, Ghosh S: TLR signalling augments macrophage bactericidal activity through mitochondrial ROS. Nature 2011, 472:476-480.

53. Zhou R, Yazdi AS, Menu P, Tschopp J: A role for mitochondria in NLRP3 inflammasome activation. Nature 2011, 469:221-225.

54. Robbins GR, Wen H, Ting JP: Inflammasomes and metabolic disorders: old genes in modern diseases. Mol Cell 2014, 54:297-308.

55. Arnoult D, Soares F, Tattoli I, Girardin SE: Mitochondria in innate immunity. EMBO Rep 2011, 12:901-910.

56. Tschopp J, Schroder K: NLRP3 inflammasome activation: The convergence of multiple signalling pathways on ROS production? Nat Rev Immunol 2010, 10:210-215.

57. Nakahira K, Haspel JA, Rathinam VA, Lee SJ, Dolinay T, Lam HC, Englert JA, Rabinovitch M, Cernadas M, Kim HP, Fitzgerald KA, Ryter SW, Choi AM: Autophagy proteins regulate innate immune responses by inhibiting the release of mitochondrial DNA mediated by the NALP3 inflammasome. Nat Immunol 2011, 12:222-230.

58. Hoogenraad NJ, Ward LA, Ryan MT: Import and assembly of proteins into mitochondria of mammalian cells. Biochim Biophys Acta 2002, 1592:97-105.

59. Haynes CM, Petrova K, Benedetti C, Yang Y, Ron D: ClpP mediates activation of a mitochondrial unfolded protein response in $C$. elegans. Dev Cell 2007, 13:467-480.

60. Nargund AM, Pellegrino MW, Fiorese CJ, Baker BM, Haynes CM: Mitochondrial import efficiency of ATFS-1 regulates mitochondrial UPR activation. Science 2012, 337:587-590.

61. Durieux J, Wolff S, Dillin A: The cell-non-autonomous nature of electron transport chain-mediated longevity. Cell 2011, 144:79-91.

62. Houtkooper RH, Mouchiroud L, Ryu D, Moullan N, Katsyuba E, Knott G, Williams RW, Auwerx J: Mitonuclear protein imbalance as a conserved longevity mechanism. Nature 2013, 497:451-457.

63. Randow F, Youle RJ: Self and nonself: how autophagy targets mitochondria and bacteria. Cell Host Microbe 2014, 15:403-411.

64. Breitenbach M, Rinnerthaler M, Hartl J, Stincone A, Vowinckel J, Breitenbach-Koller H, Ralser M: Mitochondria in ageing: there is metabolism beyond the ROS. FEMS Yeast Res 2013. doi:10.1111/1567-1364.12134.

65. Gomes LC, Scorrano L: Mitochondrial morphology in mitophagy and macroautophagy. Biochim Biophys Acta 1833, 2013:205-212.

66. Kaelin WG Jr, McKnight SL: Influence of metabolism on epigenetics and disease. Cell 2013, 153:56-69.

67. Wellen KE, Hatzivassiliou G, Sachdeva UM, Bui TV, Cross JR, Thompson CB: ATP-citrate lyase links cellular metabolism to histone acetylation. Science 2009, 324:1076-1080.

68. Shyh-Chang N, Locasale JW, Lyssiotis CA, Zheng Y, Teo RY, Ratanasirintrawoot S, Zhang J, Onder T, Unternaehrer JJ, Zhu H, Asara JM, Daley GQ, Cantley LC: Influence of threonine metabolism on S-adenosylmethionine and histone methylation. Science 2013, 339:222-226.

69. Wang J, Alexander P, MCKnight SL: Metabolic specialization of mouse embryonic stem cells. Cold Spring Harb Symp Quant Biol 2011, 76:183-193.

70. Xiong Y, Guan KL: Mechanistic insights into the regulation of metabolic enzymes by acetylation. J Cell Biol 2012, 198:155-164.

71. Hardie DG, Ross FA, Hawley SA: AMPK: a nutrient and energy sensor that maintains energy homeostasis. Nat Rev Mol Cell Biol 2012, 13:251-262.
72. Antonioli L, Blandizzi C, Pacher P, Hasko G: Immunity, inflammation and cancer: a leading role for adenosine. Nat Rev Cancer 2013, 13:842-857.

73. Colgan SP, Eltzschig HK: Adenosine and hypoxia-inducible factor signaling in intestinal injury and recovery. Annu Rev Physiol 2012, 74:153-175.

74. Friedman JR, Nunnari J: Mitochondrial form and function. Nature 2014, 505:335-343.

75. Campello S, Scorrano L: Mitochondrial shape changes: orchestrating cell pathophysiology. EMBO Rep 2010, 11:678-684

76. Al-Mehdi AB, Pastukh VM, Swiger BM, Reed DJ, Patel MR, Bardwell GC, Pastukh W, Alexeyev MF, Gillespie MN: Perinuclear mitochondrial clustering creates an oxidant-rich nuclear domain required for hypoxia-induced transcription. Sci Signal 2012, 5:ra47.

77. Chan DC: Fusion and fission: interlinked processes critical for mitochondrial health. Annu Rev Genet 2012, 46:265-287.

78. Kasahara A, Cipolat S, Chen Y, Dorn GW 2nd, Scorrano L: Mitochondrial fusion directs cardiomyocyte differentiation via calcineurin and Notch signaling. Science 2013, 342:734-737.

79. Hoppins S, Nunnari J: Mitochondrial dynamics and apoptosis-the ER connection. Science 2012, 337:1052-1054.

80. Rizzuto R, Pinton P, Carrington W, Fay FS, Fogarty KE, Lifshitz LM, Tuft RA, Pozzan T: Close contacts with the endoplasmic reticulum as determinants of mitochondrial Ca2+ responses. Science 1998, 280:1763-1766.

81. van Vliet AR, Verfaillie T, Agostinis P: New functions of mitochondria associated membranes in cellular signaling. Biochim Biophys Acta 2014

82. Nunnari J, Suomalainen A: Mitochondria: in sickness and in health. Cell 2012, 148:1145-1159.

doi:10.1186/1741-7007-12-34

Cite this article as: Chandel NS: Mitochondria as signaling organelles. BMC Biology 2014 12:34. 